\title{
Integrated Information System for Early Detection of Maternal Risk Factors Based on Continuum of Care Approach of Mother and Toddler Cohorts
}

\author{
Nyoman Anita Damayanti ${ }^{1}$, Darmawan Setijanto ${ }^{2}$, Arief Hargono ${ }^{1}$, Ratna Dwi Wulandari ${ }^{1}$, \\ Maya Weka Santi ${ }^{3}$, Benny Tjahjono ${ }^{4}$, Aulia Ramadhani ${ }^{2}$ \\ 'Faculty of Public Health, Universitas Airlangga, Surabaya, Indonesia \\ ${ }^{2}$ Faculty of Dental Medicine, Universitas Airlangga, Surabaya, Indonesia \\ ${ }^{3}$ Health Department, State Polytechnic of Jember, Jember, Indonesia \\ ${ }^{4}$ Centre for Business in Society, Coventry University, Coventry, UK
}

Objectives: The aim of this study is to demonstrate how an integrated information system of mother and toddler cohorts can be developed as a basis of the continuum of care approach that subsequently can be used as the basis of early detection of risk factors of maternal mortality. Methods: This research was carried out qualitatively. The data was collected through three techniques: in-depth interviews, focus group discussion, and document studies at six public health centers located in four sub-districts of Surabaya, Indonesia. This research was conducted from 2016 to 2018. Results: The data collected from this research has become a basis input data requirement analysis for an integrated mother and toddler cohort information system. The system accommodates all the variables in each period of pre-marriage, pregnancy, labor, infancy and toddlerhood. The system facilitates healthcare workers to retrieve data and information related to mother and toddler health status. Conclusions: The availability of various pieces of information enables the health status of mothers and toddlers to be monitored thoroughly throughout their long-life cycle. This continuum of care approach is beneficial in the early detection and management of risk factors of maternal mortality, such as pregnancy complications as well as childbirth and postpartum complications.

Keywords: Information Systems, Maternal-Child Health Services, Continuum of Care, Delivery of Health Care

Submitted: February 13, 2019

Revised: 1st, April 21, 2019; 2nd, May 16, 2019

Accepted: July 1, 2019

\section{Corresponding Author}

Nyoman Anita Damayanti

Department of Health Administration and Policy, Faculty of Public Health, Universitas Airlangga, Surabaya, Indonesia. Tel: +62315920948, E-mail: nyoman.anita3@gmail.com (https://orcid. org/0000-0001-5906-738X)

This is an Open Access article distributed under the terms of the Creative Commons Attribution Non-Commercial License (http://creativecommons.org/licenses/by$\mathrm{nc} / 4.0 /$ ) which permits unrestricted non-commercial use, distribution, and reproduction in any medium, provided the original work is properly cited.

(C) 2019 The Korean Society of Medical Informatics

\section{Introduction}

East Java is a province in Indonesia with the maternal mortality rate of 93.52 per 100,000 live births and the child mortality rate of 26.66 per 1,000 live births in 2014. Most maternal mortality cases in East Java in 2014 and 2015 were due to pre-eclampsia/eclampsia, followed by postpartum hemorrhage of $25.57 \%$ and $25.05 \%$, respectively [1]. Decreasing maternal and child mortality is important point in achieving sustainable development goals (SDGs). About 830 women die from pregnancy- or childbirth-related complications around the world every day [2]. The SDG targets for 
2030 are to decrease maternal mortality to 70 per 100,000 live births, child mortality to 25 per 1,000 live births, and neonatal mortality to 12 per 1,000 live births [3].

Around 5\% to $8 \%$ of women in developing countries with pre-eclampsia will experience eclampsia [4]. Maternal deaths during pregnancy and postpartum have several causes that may arise during pregnancy. Lack of health information during pregnancy can lead to death both during pregnancy or childbirth [2]. In Indonesia, Canada, and various countries, hypertension during pregnancy is a major cause of maternal and perinatal death. Mothers suspected of pre-eclampsia must undergo testing to determine the condition of organ dysfunction so that further diagnosis can be made [5].

Pre-eclampsia can cause risks to babies, including growth disruption and prematurity [6]. Because premature babies have a high risk of experiencing medical complications, it is important to do an early assessment of the premature labor risk. For this reason, this integrated cohort information system is needed from the time of pregnancy followed by a baby cohort.

Based on discussions with the East Java Commission on the Reduction of Maternal and Infant Mortality Rates (PENA$\mathrm{KIB}$ ), one of the causes of high maternal mortality and infant mortality is the lack of early detection of risk factors. Like maternal mortality, risk factors for infant mortality can be determined through surveillance efforts or early detection of risk factors for infant mortality.

\section{Continuum of Care Approach}

The relationships between mothers, babies, and toddlers cannot be separated in life or in the need for health services. Babies' health condition is very much determined by the condition of their mothers. Maternal health status can be used as a risk factor predictor for the mother and the baby she conceived and bore. Babies' health condition can be used as a predictor of risk to the babies themselves and further when they grow into toddlers. Early detection of risk factors can therefore be realized by an effective, comprehensive, and integrated understanding of health status in the continuum of care [7].

Continuum of care is a holistic and coordinated service system design for managing service and operation in an integrated system [8]. An important principle in developing an integrated maternal, newborn, and child health $(\mathrm{MNCH})$ program is a continuum of care. This means that healthcare must be provided as a continuum in the life cycle consisting of teenagers/premarital, pregnancy, birth, and infancy [9].

Adopting the continuum of care approach requires large amounts of data collected from all stages of the human life cycle, which can be obtained from various sources and available for a long period of time. In this way, risk can be detected as early as possible according to the period in the life cycle.

At present, the recording and reporting of information of mother and toddler cohorts is still done manually and in many different places, mostly using paper-based systems. This poses a great deal of difficulty in ensuring accuracy of the data as paper-based systems have a limited life and are normally destroyed after a certain period of time due to space limitations. The adoption of a continuum of care approach requires effective and efficient collection and storage of accurate data over a long time span. The development of a computer-based information system would therefore facilitate data storage and retrieval, and would enable intelligent data processing or compilation so that information can be given accurately and quickly to benefit patients.

\section{Combination of Information System and Method for Development}

The information system is a combination of the following five elements: human, data, software, hardware, and network. These five elements are organized together to transform inputs into outputs by processing the data into information [10]. Silver et al. [11] state that the aim of an information system implemented in an organization is to improve the efficiency and effectiveness of the organization. The system development life cycle (SDLC) framework allows system designers and developers to follow a sequence of activities [12]. The SDLC consists of several stages, namely, user requirements, requirements analysis, system design, system development, testing, and acceptance [10].

\section{Methods}

The research was conducted qualitatively at six public health centers located in four sub-districts in Surabaya, East Java, Indonesia, between 2016 and 2018. The information system was developed following the SDLC framework, which provides system designers and developers with the following sequence of activities [13]: (1) system investigation, (2) system analysis, (3) system design, (4) system implementation, and (5) system maintenance and evaluation. This is in accordance with Lemke [13] stating that SDLC consists of several phases, namely, planning and needs analysis, design and development, implementation, testing, integration and maintenance. In this study, the SDLC stages were followed 
only until the third stage, system design.

In the system investigation, the need for information system development was analyzed in relation to existing problems. In the system design, specifications were developed for the hardware, software, people, network, data resources and the information products that would satisfy the functional requirements of the proposed information system [14]. In this research, the system was assessed by SWOT analysis.

\section{Data Collection}

Data were collected through three techniques, namely: indepth interviews, focus group discussion (FGD), and document studies. Data collection through in-depth interviews and FGD was preceded by requests for approval from respondents through filling out informed consent. Data collection in this study was in accordance with research by Like et al. [15] conducted in Papua New Guinea. The FGD conducted in this study was an interactive discussion that focused on specific issues between six to eight predetermined participants and led by a moderator, which aimed to gain a broad range of views on the research topic over a 60- to 90-minute period [16]. Document studies were conducted by collecting, recording, and reporting documents used in the mother and toddler health program in Surabaya. The respondents of in-depth interviews and FGD were stakeholders related to the mother and toddler health efforts, including midwives, pediatricians, heads of the health centers, staff of Surabaya District Health Office and East Java Provincial Health Office, representatives of the Indonesian Midwives Association, representatives of the Indonesian Obstetrics and Gynecology Association and the Commission on the Reduction of Maternal and Infant Mortality Rates.

\section{System Development and Implementation}

Data collected for the development of this system included identification of system input and output entities, types of

Table 1. Strengths and weaknesses of recording and reporting systems of mother and toddler cohorts in Surabaya

\begin{tabular}{ll}
\hline \multicolumn{1}{c}{ Strengths } & \multicolumn{1}{c}{ Weaknesses } \\
\hline - There was already a standard form of recording and & - There were no record systems for the pre-marital period. \\
reporting documents. & - The existing recording documents were still fragmented and \\
- Variables in recording and reporting documents were & not integrated. \\
completed and detailed covering mother and toddler & - The recording and reporting system of mother and toddler \\
conditions, so they can be used by medical personnel in & data every month are still done manually. This is very burden- \\
making decisions. & some for some health workers. \\
- There was a web-based recording and reporting system in & - The recording of mother and toddler health conditions is \\
public health center. & incomplete. \\
- There were available numbers of midwives in Surabaya & - The requested reporting format often changes. \\
public health centers. & - There were difficulties in tracing data of mother and toddler \\
- Most of the midwives in public health centers know and & health conditions. \\
understand how to record and analyze data. & - Many types of health information had to be reported to the \\
- The midwives could operate computer-based information & District Health Office. \\
system. & \\
- The recording and reporting were done regularly (monthly). & \\
- Wi-Fi and Internet were available. & \\
\hline
\end{tabular}

Table 2. Opportunities and challenges of recording and reporting systems of mother and toddler cohorts in Surabaya

\begin{tabular}{|c|c|}
\hline Opportunities & Challenges \\
\hline $\begin{array}{l}\text { - Full support from the city mayor of Surabaya for mother } \\
\text { and child health. }\end{array}$ & $\begin{array}{l}\text { - System vulnerability because of external threats, such as } \\
\text { viruses, hackers, etc. }\end{array}$ \\
\hline - Regulation of Health Ministry Number 511 in 2002 about & - Difficulty of system maintenance. \\
\hline Policy and Strategy for the Development of the National & - Recording formats in clinics and hospitals were not referred to \\
\hline $\begin{array}{l}\text { Health Information System encourages health centers to } \\
\text { apply the computer-based information system. }\end{array}$ & cohort-based records. \\
\hline
\end{tabular}


data requirements, data sources, procedures for recording and reporting data, as well as the flow of data to information generated. This system is expected to be used by health workers in centers for prenatal and postnatal healthcare and information for women and toddlers or hospitals to record services provided to mothers, infants, and children in an integrated manner.

For the prototype of risk factor surveillance information systems and mother and toddler cohorts, an entity relationship diagram (ERD). Internal testing was performed as a preparation for external trials with the officers of the public health centers and Surabaya District Health Office. The data input into the system was data of mother and toddler cohorts in the health centers.

\section{Results}

Based on the results of system investigation, the mother and toddler health recording system in Surabaya, Indonesia, currently has not been integrated; instead, the information is recorded manually. Information about maternal, infant, and toddler mortality risk factors has not been well-documented. A software requirements specification (SRS) document was

Table 3. Variables and information required for the information system development of mother and toddler risk factor surveillance and cohorts

\begin{tabular}{|c|c|}
\hline Life period & Variable required \\
\hline \multirow[t]{2}{*}{ Pre-marriage } & Identity of wife and husband \\
\hline & Health and immunization status \\
\hline \multirow[t]{5}{*}{ Pregnancy } & Early pregnancy condition \\
\hline & Immunization status \\
\hline & Antenatal care examination \\
\hline & Screening of high-risk pregnancy \\
\hline & Referral plan or delivery plan \\
\hline \multirow[t]{5}{*}{ Delivery baby } & Information about the delivery process \\
\hline & Information about referral and backward referral \\
\hline & Maternal conditions \\
\hline & Health problems postpartum \\
\hline & Contraceptive status \\
\hline \multirow[t]{3}{*}{ Infant } & Identity of newborn \\
\hline & Health status of newborn \\
\hline & Infant risk factor \\
\hline \multirow[t]{4}{*}{ Toddler } & Immunization status \\
\hline & Health status \\
\hline & Nutrition status \\
\hline & Child growth \\
\hline
\end{tabular}

created during this phase containing information about how the system is able to meet user needs.

Another stage of SDLC is system assessment by SWOT analysis. Based on the FGD and in-depth interview results with several stakeholders, the strengths, weaknesses, opportunities, and challenges of the use of the integrated mother and toddler cohort information system existing currently can be identified as shown in Tables 1 and 2. From Tables 1 and 2, it can be seen that the system of recording and reporting on mother and toddler cohorts in Surabaya has more strengths than weaknesses.

Based on the results of the FGD, the variables and information required for the information system development as well as the risk factor surveillance and cohorts of mother and toddlers are shown in Table 3. The results of FGD and document studies were used to create a data flow diagram (DFD). DFDs of the risk factor surveillance information system as well as mother and toddlers cohorts based on the phase of continuum of care are presented in Figure 1.

As seen in Figure 1, all types of data required by the health centers and related stakeholders can be accommodated. The work flow process of the integrated mother and toddler cohorts information system based on the phase of continuum of care is shown in Figure 2. Based on the results of the study, the ERD of the prototype information system that has been developed is presented in Figure 3.

\section{Discussion}

The study findings show that there are numerous operational problems related to the Health Management Information System (HMIS). Therefore, the implementation of information systems in the health sector is not only based on the encouragement of routine health data and information needs, but also the availability of adequate supporting resources must be available [17].

Based on the study findings, the recommendations for strengthening the HMIS so that it can support the Maternal and Child Health Program are to use computers for the HMIS at public health centers for data entry. Moreover, the data collection and reporting formats should be standardized and should not be changed frequently [18]. System design that can present data for daily work and the use of upto-date software are keys to the effective use of information systems [19]. Reforming health information systems with better quality and quantity of patient data, development of an information system that integrates all subsystems with clear and organized work flows, and restructuring of data to 


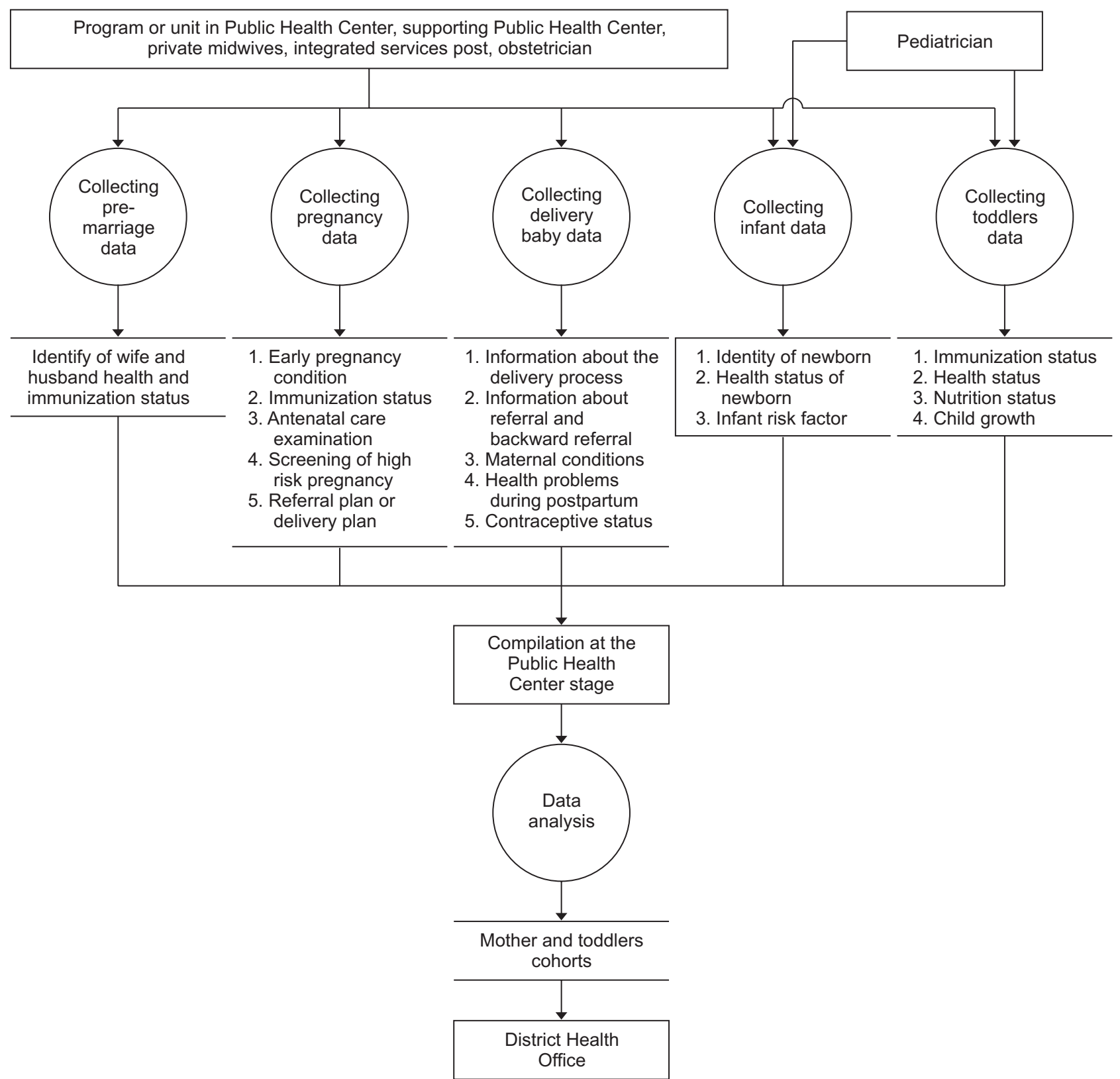

Figure 1. Data flow diagram of the information system of integrated mother and toddler cohorts based on continuum of care.

be clearer and interrelated are needed [20].

The system analysis stage assesses variables in the information systems and cohorts of mothers, infants, and toddlers. The variables in the recording and reporting of mother and toddler cohort documents were used as the basis of system variable arrangement. The purpose of system analysis is to understand and prioritize the gaps that exist in the current system and how the system development will address these gaps [21]. In this study, we found that one of the gaps is the incomplete data in the existing recording and reporting documents. Furthermore, FGD was conducted to deal with gaps related to data on the recording of maternal and infant health status. Some new variables were added to the system based on the discussion with the appropriate stakeholders through FGD. The FGD results and document studies were used to create a DFD.

With the proposed health information system, all types of data required by health centers and related stakeholders can be accommodated. The data recorded by healthcare facilities will be gathered at the public health center and will subsequently be reported to the District Health Office. The proposed model for the maternal and child health information system will enable trend analysis for policy making to help accelerate the efforts for meeting global maternal and child health targets [22].

External trials were carried out with the following technical 
Arrival of pregnant women

and examination in Public Health Center

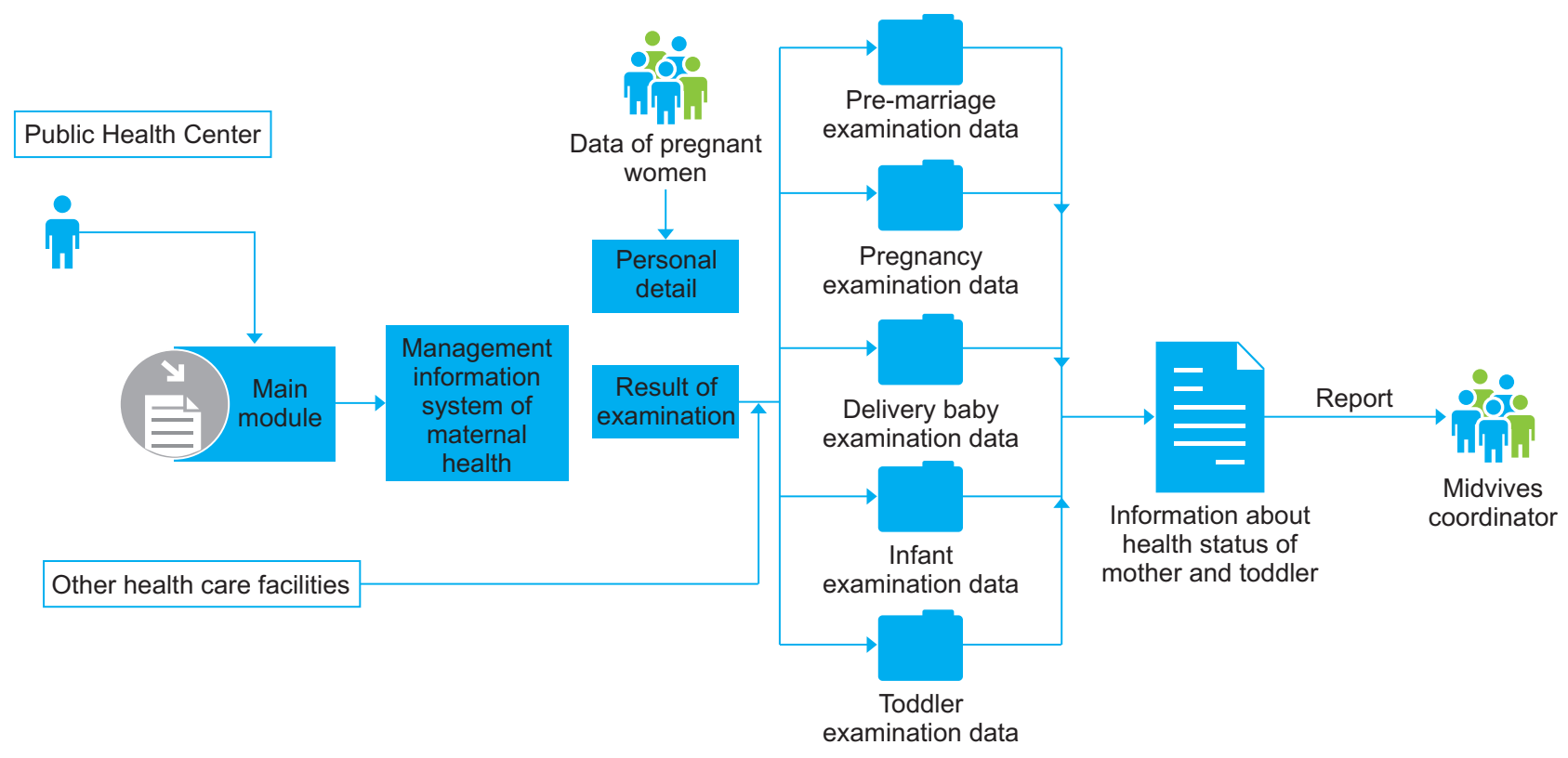

Figure 2. Work flow of the integrated mother and toddler cohorts information system.

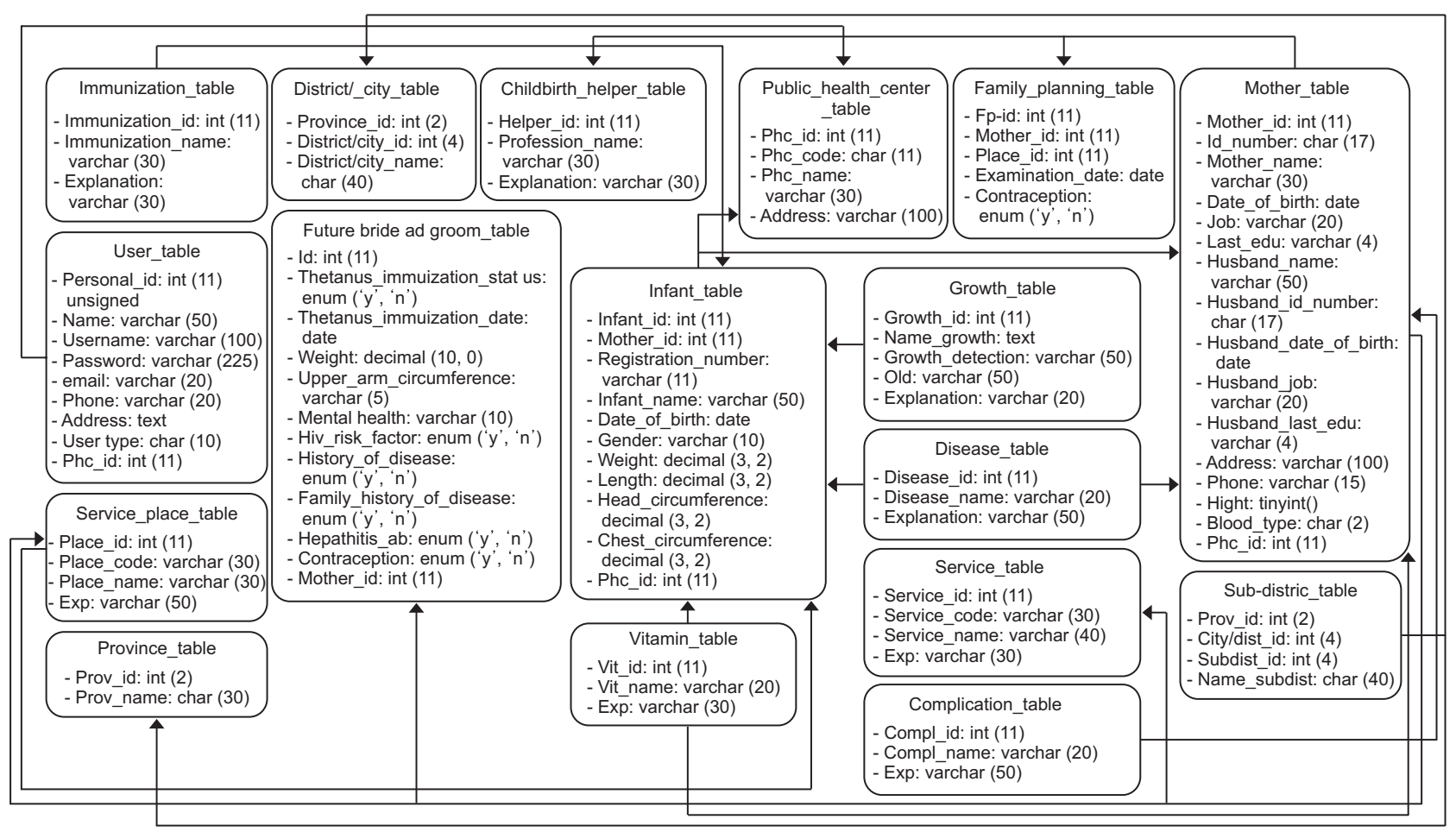

Figure 3. Entity relationship diagram of information system development of mother and toddler integrated cohorts.

steps. The midwives or staff of the health office of Surabaya operated the computers connected to the internet to access the web-based information system. The trial participants provided data of mother and infant cohorts as material for input into the system. During the trial much information and many suggestions were collected from the participants regarding ways to improve the information system of maternal and infant cohorts.

Most of the midwives or staff of the health office of Surabaya said that the software could facilitate health workers in conducting risk factor surveillance. Moreover, early detection and prevention can be conducted as early as possible to 
reduce the maternal and infant mortality rates in Surabaya. However, obstacles were found; although software is used, there is still a necessity to write manually.

During the external trials, some input was obtained from participants regarding how to improve the existing variables of the inputting data form. The programmers and researchers were responsible for modifying the systems based on the health workers' input as participant in the external trials. This was done to generate high-quality systems that would meet users' needs [23]. Previous studies have shown that health information technology has a variety of important benefits in terms of quality and efficiency of service delivery based on the guidelines regarding prevention, increasing monitoring and surveillance, reducing medication errors, and reducing the potential for excessive or unnecessary service [24]. Technology can be very useful, but it is still necessary to consider the complexity of the system.

\section{Conflict of Interest}

No potential conflict of interest relevant to this article was reported.

\section{Acknowledgments}

We sincerely thank the Ministry of Research Technology and Higher Education, United Nations Children's Fund (UNI$\mathrm{CEF}$ ), Indonesian Midwives Association, National Board of Population and Family Planning, Commission on the Reduction of Maternal and Infant Mortality Rates, Section Chief of Family Health Program, Surabaya District Health Office and East Java Provincial Health Office, head of health centers, obstetricians, gynecologists and pediatricians in Surabaya who provide inputs and supports. The product of this research will not be possible without all of them.

\section{ORCID}

Nyoman Anita Damayanti (http://orcid.org/0000-0001-5906-738X)

Darmawan Setijanto (http://orcid.org/0000-0001-7182-2712)

Arief Hargono (http://orcid.org/0000-0001-8978-9877)

Ratna Dwi Wulandari (http://orcid.org/0000-0003-4365-5747)

Maya Weka Santi (http://orcid.org/0000-0003-4474-2965)

Benny Tjahjono (http://orcid.org/0000-0001-7503-7500)

Aulia Ramadhani (http://orcid.org/0000-0001-6400-6741)

\section{References}

1. East Java Provincial Health Office. Health profile of East Java Province in 2014. Surabaya, Indonesia; East Java Provincial Health Office; 2014.

2. Word Health Organization. Maternal mortality [Internet]. Geneva, Switzerland: Word Health Organization; c2019 [cited at 2019 Apr 21]. Available from: https:// www.who.int/news-room/fact-sheets/detail/maternalmortality.

3. Word Health Organization. Sustainable Development Goals 3: Health [Internet]. Geneva, Switzerland: Word Health Organization; c2019 [cited at 2019 Apr 21]. Available from: https://www.who.int/topics/sustainabledevelopment-goals/targets/en/.

4. Steegers EA, von Dadelszen P, Duvekot JJ, Pijnenborg R. Pre-eclampsia. Lancet 2010;376(9741):631-44.

5. Magee LA, Helewa M, Rey E; Hypertension Guideline Committee; Strategic Training Initiative in Research in the Reproductive Health Sciences (STIRRHS) scholars. Diagnosis, evaluation, and management of the hypertensive disorders of pregnancy. J Obstet Gynaecol Can 2008;30(3 Suppl):S1-S2

6. Duley L. The global impact of pre-eclampsia and eclampsia. Semin Perinatol 2009;33(3):130-7.

7. Word Health Organization. Chapter 3: Monitoring NCDs and their risk factors: a framework for surveillance [Internet]. Geneva, Switzerland: Word Health Organization; c2016 [cited at 2019 May 16]. Available from: https://www.who.int/nmh/publications/ncd_report_chapter3.pdf.

8. Evashwick C. The continuum of long-term care. 3rd ed. New York (NY): Thomson/Delmar Learning; 2005.

9. Lawn J, Kerber K. Opportunities for Africa's newborns: practical data policy and programmatic support for newborn care in Africa. Cape Town, South Africa: Partnership for Maternal, Newborn and Child Health; 2006. p. 24-8.

10. Buragga KA, Zaman N. Software development techniques for constructive information systems design. Hershey, PA: IGI Global; 2013. p. 118-23.

11. Silver MS, Markus ML, Beath CM. The information technology interaction model: a foundation for the MBA core course. MIS Q 1995;19(3):361-90.

12. The Institute of Chartered Accountants of India. Information system control and audit. Nagpur, India: The Institute of Chartered Accountants of India; 2015.

13. Lemke G. The software development life cycle and its 
application [thesis]. Ypsilanti (MI): Eastern Michigan University; 2018.

14. O’Brien JA, Marakas GM. Management information systems. 10th ed. New York (NY): McGraw-Hill; 2011.

15. Like P, Sahama TR, Windsor CA, Huxley C. Designing a quality health information system: case study analysis of maternal and child health in Papua New Guinea. Proceedings of the 51st Annual Medical Symposium Advancing Women's Health through Innovation; 2015 Aug 30-Sep 2; Papua New Guinea.

16. Hennink MM. Focus group discussions. New York (NY): Oxford University Press; 2014.

17. Lippeveld T, Sauerborn R, Bodart C. Design and implementation of health information systems. Geneva, Switzerland: World Health Organization; 2000.

18. Bhattacharya M, Shahrawat R, Joon V. Understanding level of maternal and child health indicators used in Health Management Information System among peripheral level health functionaries in two districts of India. J Health Inform Dev Ctries 2012;6(1):385-95.

19. Ovretveit J, Nelson E, James B. Building a learning health system using clinical registers: a non-technical introduction. J Health Organ Manag 2016;30(7):110518.

20. Soontornpipit P, Taratep C, Teerawat W, Satitvipawee P, Piroonratana T. The study of hospital information systems in the 8 th health region. Procedia Comput Sci 2016;86:252-6.

21. McBride S, Tietze M. Nursing informatics for the advanced practice nurse: patient safety, quality, outcomes, and interprofessionalism. New York (NY): Springer Publishing Company; 2016.

22. Ismail S, Alshmari M, Latif K, Ahmad HF. A granular ontology model for maternal and child health information system. J Healthc Eng 2017;2017:9519321.

23. Word Health Organization. Risk factors [Internet]. Geneva, Switzerland: Word Health Organization; c2017 [cited at 2019 Apr 21] Available from: http://www.who. int/topics/risk_factors/en/.

24. Chaudhry B, Wang J, Wu S, Maglione M, Mojica W, Roth E, Morton SC, Shekelle PG. Systematic review: impact of health information technology on quality, efficiency, and costs of medical care. Ann Intern Med 2006;144(10):742-52. 